\title{
Right to die in Canada: respecting the wishes of physician conscientious objectors
}

\author{
John Fletcher MB BChir MPH
}

$\mathrm{O}$ n Feb. 6, 2016, it is likely to become legal in Canada for a physician to aid a patient in dying. For physicians who believe this is a compassionate change in the law, the remaining questions of how to go about this are administrative. Their convictions and the law would be in alignment.

However, $63 \%$ of Canadian physicians say they would refuse to provide medical aid in dying and so may find their convictions at odds with the law. ${ }^{1}$ The law is likely to give their patients the right to seek medical aid in dying, yet they as physicians would not wish to take part in that step. Clearly, doctors have no business denying patients their newly recognized right, no matter how strongly they may feel. But where does this leave physicians who, for whatever reason, do not wish to be involved with helping their patients to gain access to medical aid in dying? Those who would refuse, not only to offer medical aid in dying themselves, but also to refer a patient to another doctor for such a service, argue that referral would make them guilty by association of an act that they see as wrong. They have a point.

Canada has a tradition of respecting conscientious objection, and we should be wary of compelling anyone, including doctors, to act against their own moral compass. Yet some of the rhetoric surrounding implementation of the impending change in the law appears to be suggesting just that, as patients' rights are pitted against doctors' rights. The Quebec health minister recently referred to the attitude of a group of palliative care doctors who did not want to offer medical aid in dying as "inappropriate and unfortunate." 2 The Canadian Medical Association's draft framework document on medical aid in dying supports conscientious objection, but suggests that physicians should refer patients for medical aid in dying if they are not willing to provide the service themselves. ${ }^{3}$ An update to this policy, published while this article was going to press, removes the requirement for referral. The CMA General Council meeting in August of this year went further when a motion to support conscientious objectors who refuse to refer their patients for medical aid in dying was defeated by a $79 \%$ vote against. ${ }^{4}$ If doctors are to be compelled to aid their patients to access medical aid in dying, then they are not being allowed to follow their consciences at all.

Overriding conscientious objection to medical aid in dying would be damaging to the medical profession and is not necessary to ensuring that a patient's right of access to this form of care is upheld. Abortion services are available to women in Canada, and at the same time, doctors who do not wish to be part of the referral process have been able to opt out without reprisals or professional censure. We have accommodated conscientious objection to abortion, and we must do the same for medical aid in dying.

Canada's medical profession must now work to put in place a robust system that assures patients of their new right. Simply saying that doctors may give medical aid in dying or should refer to someone who will is not adequate, because many doctors will be reluctant, leaving vulnerable patients and their caregivers fighting their own doctor for their rights.

We need a new service that will provide patients with information and the help they need in making decisions about the care they would like toward the end of life and an easy referral pathway for that care whether that be social support, the best palliative care available in their area or medical aid in dying. This service should be made available directly to patients and at the same time doctors should have a duty to inform their patients of how to access this service. Such a specialized consulting service for all aspects of end-of-life care would enable physicians with conscientious objections to medical aid in dying to provide their patients with care while not standing in the way of their rights.

The medical profession has defined itself since the time of Hippocrates as one that "will not administer poison to anyone," and this trust forms an essential backdrop to the doctorpatient relationship during end-of-life care. Canadian society may soon allow some doctors to redefine their role, but this should not compel the majority of physicians who are not comfortable with this to abandon their convictions.

\section{References \\ 1. Vogel L. Many doctors won't provide assisted dying. CMAJ 2015;187:E409-10. \\ 2. Lambert S. Quebec health minister insists dying patients must get help to ease suffer- ing. The Canadian Press; 2015 Sept. 2. Available: www.ctvnews.ca/politics/quebec -health-minister-insists-dying-patients-must-get-help-to-ease-suffering-1.2545484 (accessed 2015 Oct. 22). \\ 3. Canadian Medical Association draft policy document. Principles-based approach to assisted dying in Canada. Canadian Medical Association; 2015. Available: www.cma.ca/Assets/assets-library/document/en/advocacy/EOL/care-at-the-end-of -life-cma-framework-june2015-e.pdf (accessed 2015 Oct. 22). \\ 4. Vogel L. CMA developing assisted death guidelines. CMAJ 2015;187:E421-2.}

Competing interests: See www.cmaj.ca/site/misc/cmaj_staff.xhtml

Affiliation: Editor-in-Chief, $C M A J$

Correspondence to: $C M A J$ editor, pubs@cmaj.ca

CMAJ 2015. DOI:10.1503/cmaj.151238 